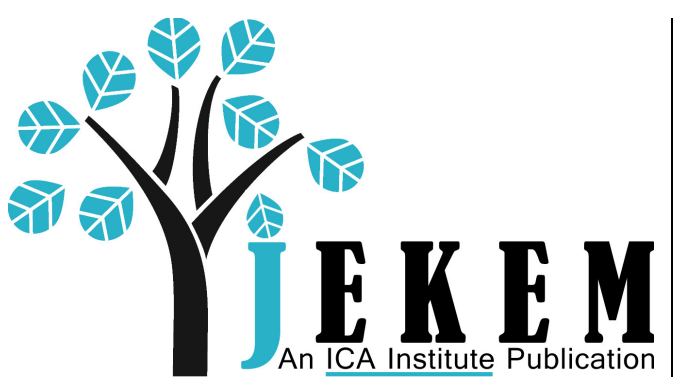

India, China ANd America Institute

1549 ClaIRMONT ROAD, SUITE 202 • DECATUR, GA 30033 USA

WWW.ICAINSTITUTE.ORG

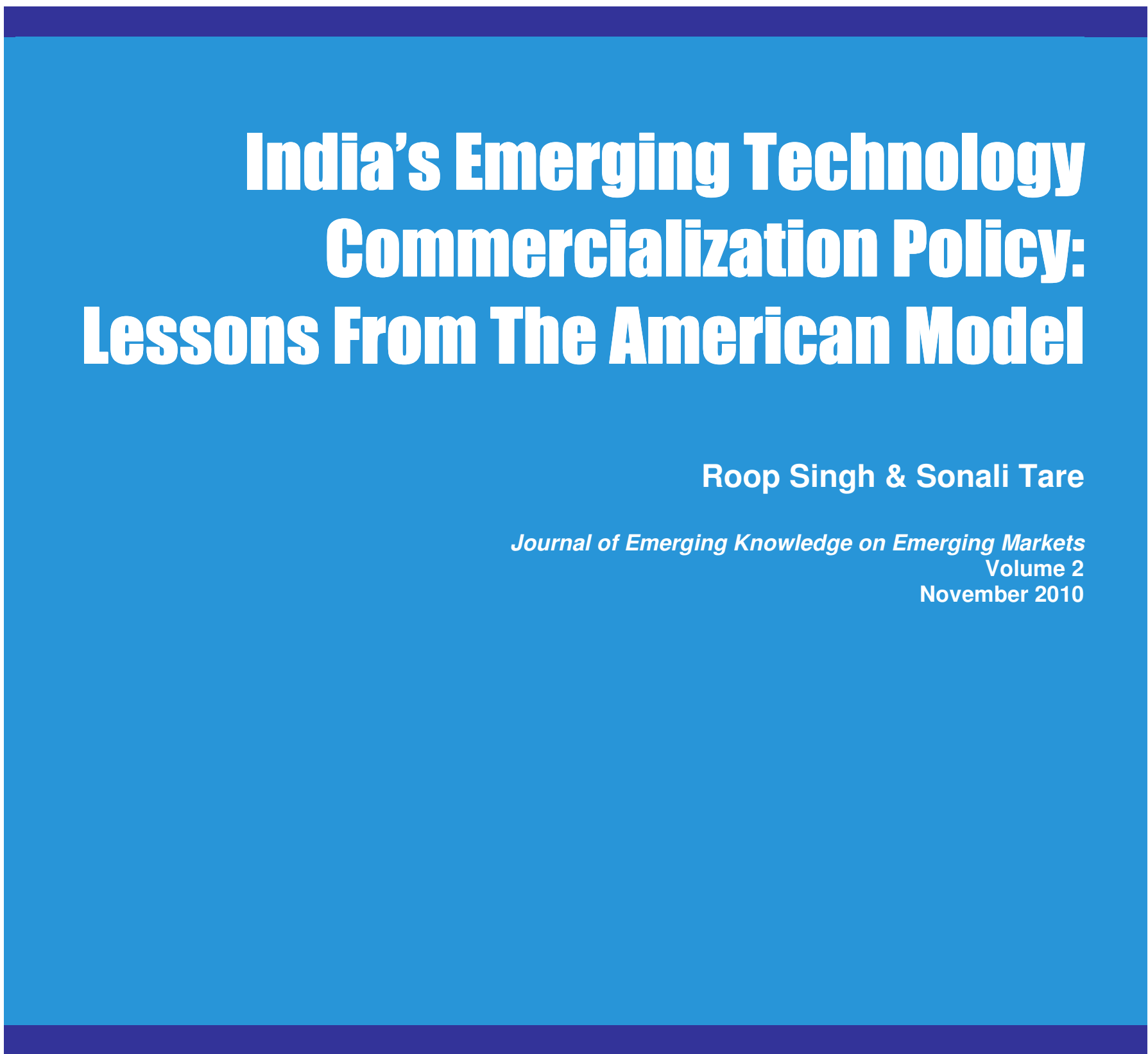




\section{India's Emerging Technology Commercialization Policy: Lessons from The American Model}

Roop Singh \& Sonali Tare

Journal of Emerging Knowledge on Emerging Markets

Volume 2

November 2010

$\mathrm{I}$ ndia is at the crossroads of its collective destiny. With an economy riddled with dichotomies, it is the $4^{\text {th }}$ largest economy based on PPP, albeit it is also the country where, 200 million people go without enough food each day.

It's economy grew at an average of 9\% from 2004-2008, and at a rate of 6.7\% in 2009 (8). The 'World Economy' fell by $2.2 \%$ in 2009 (9). It is, however, ranked $164^{\text {th }}$, according to GDP Per Capita Income, which stands at \$3100 (1). Other developing countries, like Brazil and China are ranked higher, at 106 and 128 respectively (1). According to the UNICEF, $42 \%$ of India's population lies under the international poverty line, which is defined as $\$ 1.25$ per day (3). There are an estimated 1 billion people who go hungry everyday around the world; of this number 300 million or $30 \%$ are in India (5). India is ranked 65 on the Global Hunger Index, lower than Zimbabwe.

Millions of young minds engaged in technology services industry have surely earned India the credentials of the IT capital of the world. But, is the world's largest young population driving a true 'knowledge economy'. Is India using its scientific and technological prowess for national good? Is there a policy framework in India to foster its brightest minds to innovate for millions? 
What have other countries done to innovate $\&$ commercialize innovation from the grassroots? America has had a good set of experiences in the areas of "Technology Commercialization and Licensing". Industry and Research institution alliances run quite deep in US. A lot of this is credited to the Bayh-Dole act of 1980. We believe that India's policy makers and scientific community will be served well by learning from America's experiences and adapting them to unique Indian circumstances. For India, we attempt to explain the apparent disconnect between market conditions, market opportunity and existing policy. In this working review paper we provide commentary on and explore the following research questions

- History of Tech Commercialization in US

- Emergence of industry-academia relationship: Success, Challenges and Impact

- Industry Impacts of Bayh-Dole Act in US

- Major factors under consideration while designing such a policy

1. Legal Framework

2. Contours of intellectual property law and on-ground implementation

3. Awareness of such issues in the SME community

4. Role of universities

5. What do the inventors want?

6. Do any metrics exist to measure the impact of Bayh-Dole?

7. Is data available to support the metrics?

- India's unique circumstances

- Factors impacting India's Tech Commercialization policy

- Do we need such policy in India?

- Is Bayh Dole Act relevant in India? What are the experiences of the other countries with similar acts?

- How do we measure the impact in US? Do the same metrics apply in India?

$\circ \quad$ Unique market conditions in India

- Role of Tech Commercialization in enabling SME's to build assets

We first provide commentary on the history in the US, leading towards the Bayh-Dole Act of 1980, its successes, concerns and impact. We then observe the factors India can adopt for its purposes. Next we explore the unique market conditions existing including India's historical spending in these areas. In the last sections of the paper we take a practical look at a recent World Bank framework on unleashing India's innovation and offer our 
recommendations to enhance the World Bank's framework to derive a practical policy action plan to foster enabling market conditions.

\section{The process of Technology Commercialization: A Systems View}

In order to understand the parts of the Technology Commercialization process that need to be in place, we will take a take a 'systems' view of how the process of university aided technology commercialization works in the US. We believe that the eventual economic impact that government funded R\&D coupled with technology commercialization policy, has is through the interaction of interdisciplinary complex 'systems'. The various systems involved and their high level interactions are shown below.

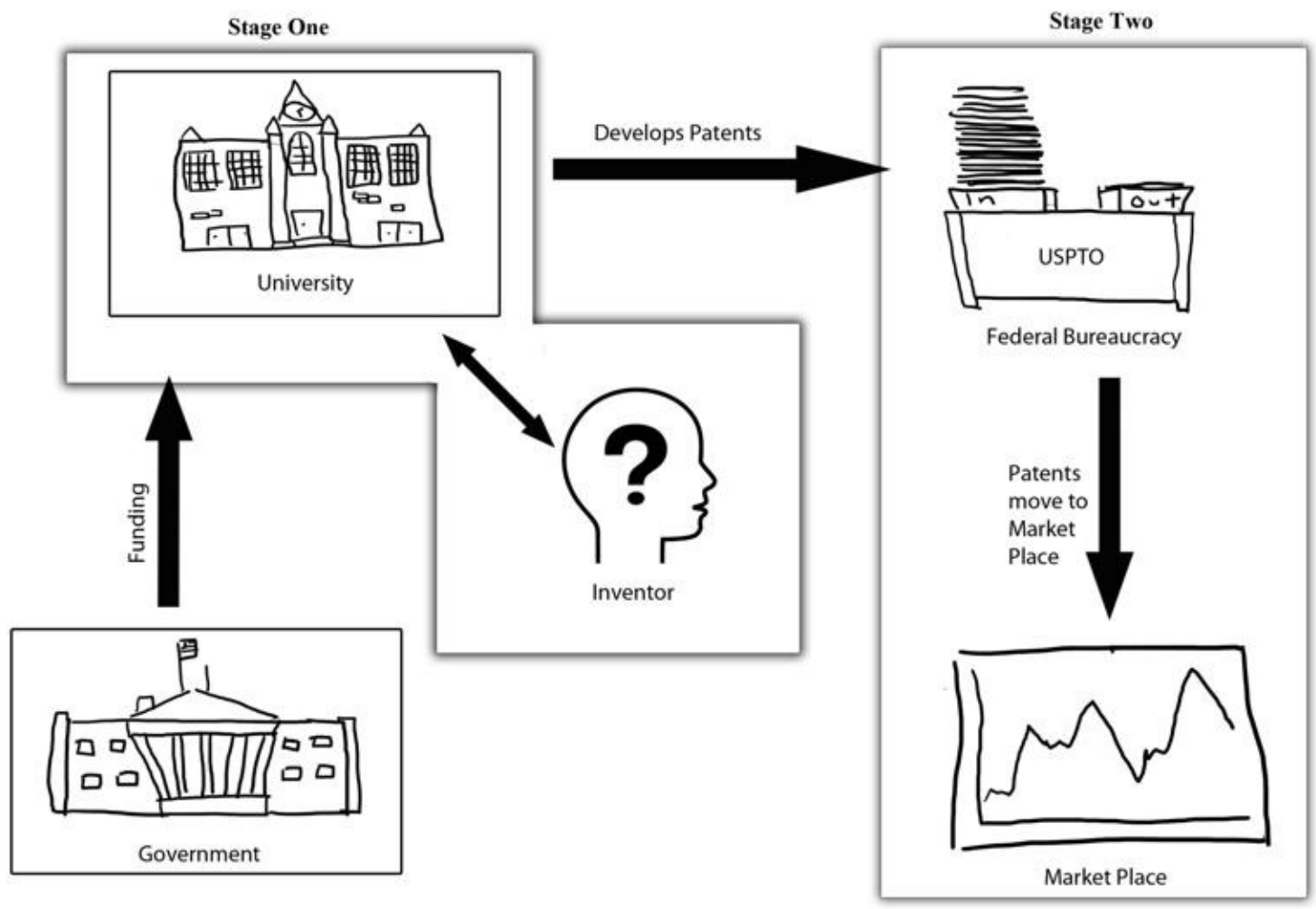

The Government: The government (all state, local and federal) funnels funding into university led research and development initiatives via different channels. For the government it becomes an investment of sorts and returns are expected on it's investments via patents filed, which some day will make their way into the market place as products and induce an economic impact.

University- Investors: Once the funding is absorbed within the university ecosystems, inventors in numerous disciplines go though the alchemy, to generate ideas, design and prototype inventions and decide to file a patent for some of those.

USPTO: The patent issuing authority is USPTO, United States Patents and Trademarks Office. 
Once the application is received, USPTO undergoes an evaluation and when the application is found to be meretricious, a patent is awarded. This process also determines for which patents the application should be filed

This process of awarding patents rights is a significant one. Once done, the asset, i.e. the invention itself, can now exist independent of the inventor. The second important result is that it can now be like a "currency" and a building block for further innovation.

Once the patent rights are established, any individual, company or organization can use this particular asset to develop a product. At this stage, we believe, it's the technology commercialization policy which shapes the outcome in the next states. If the policy has the following features

- Fair sharing of returns on any innovation going back to its original innovator and funding contributors

- A coherent and harmonized policy for regulators to follow

- Ease and effectiveness of filing patent applications

These elements set the tone for the ease and effectiveness for individuals and for corporations using patents to put out products in the market place.

Stage One: After the government funding is absorbed in the university system, to the point when patents are filed, all that happens in between, we consider as stage one.

Stage Two: Once the patent applications are filed, as they are 'sitting' within the federal bureaucracy, to the point that they placed in the market place, all that is stage two.

Now that we have a high level systems view of the technology commercialization process in US. Let us take a historical perspective of how this process and its various elements came into being.

\section{Made in the USA}

\section{A Historical Perspective}

In 2009, not a day went by without tuning into the buzz about a certain bailout, some large corporation shutting shop, a stimulus package, job losses and the like. For the first time in recent history we all witnessed debates where the effectiveness of the American version of capitalism was in question and so was the fabled American ingenuity. In an era signified by terms like "worst recession since the great depression" we are reminded of the faith \& investment put in science and technology, while we emerged from the original one in 1929. This fortitude of humanity to resurrect from adversity, paving way for a better future is deeply rooted in learning from its past. It makes us the authors, looks back on the fundamental pillars which made the US an inclusive economic growth juggernaut not so long ago, marveled by a few, emulated by a few others. 
A hallmark of America's rise to a 'free market' capitalist economy was the rapid commercialization of its patents. The Bayh-Dole Act of 1980 surely left a deep imprint on US sustainable economic development and its competitiveness. While reviewing the implications of Bayh-Dole's act in an editorial in the December 2002 issue of The Economist had this to present:

"Possibly the most inspired piece of legislation to be enacted in America over the past halfcentury was the Bayh-Dole Act of 1980. Together with amendments in 1984 and augmentation in 1986, this unlocked all the inventions and discoveries that had been made in laboratories throughout the United States with the help of taxpayers' money. More than anything this single policy measure helped to reverse America's precipitous slide into industrial irrelevance." [1]

In the words of this legislation's co-sponsor and chief architect "The Bayh-Dole Act was designed to inject the incentive of the free market into what had become a slumbering U.S. patent system. It permitted universities and small businesses to retain patent rights to inventions developed with the support of the federal government so that technology could be licensed to private companies and new products could be brought to the marketplace." [1]

Its results, he explains "All indications are that since its enactment in 1980, the Bayh-Dole Act has worked remarkably well in achieving the goals we had in mind for it. It has succeeded in moving patents off the shelves of the federal bureaucracy and into the marketplace" [1]

\section{Share The 'Goodies': The American Way}

The US Land Grant Act of 1862, granted to each state a specific amount of land, calculated according to the number of members it had in its congressional delegation. This land was mandated to be used by the states to establish universities. Though this Act was a great success, with over 70 universities being formed in the first round, the federal government did not extend its helping hand further[2]. From then on, the state governments were asked to promote the welfare of these academic institutions unaided. Now most states had certain priorities when it came to advancement of industrial goals, and in the American form of government they had significant autonomy as well. This influenced the way a state would fund the schools, and led to great importance being given to more no-nonsense curricula at state institutions of higher learning. Since private institutions in turn relied on private funds they similarly stressed the importance of matter-of-fact fields of study. The result of this was that both, state as well as private institutions, emphasized a curriculum with subjects that had practical and market pertinence. Applied knowledge creation, the kind best described by Stoke's Pasteur's quadrant increasingly became a norm. Stokes labeled "Pasteur's quadrant", the final quadrant, after Louis Pasteur's "use-inspired basic science" [3] 
Innovation, therefore, was not a new phenomenon in the American university, but a long tradition, which laid the basis for university funded research.

\section{Milestones Along The Way}

There have been several important milestones, brought about by pioneers in the march to the Bayh-Dole Act. The pioneers have been individuals, as well as organizations, who saw further ahead than most did at the time. They dealt with complex issues. Concerns regarding whether discoveries could be successfully marketed without protection for the creator were raised in the early $20^{\text {th }}$ century by Fredrick Gardner Cottrell, who invented the electrostatic precipitator for mitigating air pollution [2]. According to him commercialization of a product would be practically impossible if patents were placed in the public domain, and this formed the basis of his argument. No commercial establishment would want to invest in a venture where exclusivity was not maintained or protected. This was a fundamental issue with Technology Commercialization at the time. With the solution to this fundamental issue in mind, he formed the Research Corporation in 1912. The Research Corporation handled patents for many inventors during the 1920s and 1930s. Another institute that carried out similar work was Wisconsin Alumni Research Foundation or WARF. Today, WARF has grown into an organization that manages patents in behalf of University of Wisconsin (Madison) researchers, it licenses these patents and directs the money earned from these licenses back into research. Its first grant equaled $\$ 1200$, since then $\$ 750$ million have been channeled back into the University. These examples show that the need for legislation which would make patent commercialization easier existed long before such an act manifested.

Incidentally, similar concerns currently exist in India's patent commercialization landscape.

One of the pioneers of public-private partnership was noted American engineer and science policy maker, Vannevar Bush. In a report to Congress, presented in 1945, entitled, Science: The Endless Frontier, Bush suggested that the investment of government funds in basic science would stimulate the post-Great Depression economy. His report led to the foundation of the National Institutes of Health, the National Science Foundation, and the Office of Naval Research[2]. All these steps collectively led to increased cooperation between universities and the government. The universities started carrying out a substantial amount of research for the government, while the government in turn funded the universities research activities. The increase in government support for university funding is borne out by the numbers - in 1935, only $25 \%$ of research activities in academic institutions were funded by the federal government, this figure jumped to $70 \%$, by the end of the $1970 \mathrm{~s}$ $[2]$.

Contrary to expectations, the increase in collaboration between universities and the government did not lead to an increase in commercialization of the innovations that this partnership brought about. This, in fact, was one of the challenges of the pioneers mentioned above. The main reason for this was the lack of a coherent policy to bring these 
inventions to the public domain. There were no guidelines available to establish the patent holder in this situation. President Kennedy's Science Advisor, Jerome Wiesner attempted in 1963 to advance a policy under which federal agencies would have a consistent code to take action by. In a policy statement later the same year, President Kennedy, 'outlined a program to try to allocate property rights between the government and its contractors - including universities - to serve both the public interest and to encourage the utilization of the inventions. Rather than recommending universal adoption of either a title in the government or a title in the contractor policy, the statement set forth general guidelines for deciding under which conditions each type of policy was most appropriate. Numerous consultations and studies followed, but no major change in federal policies on technology transfer occurred.' [2].

When President Nixon took office, his administration was inclined to give federal agencies the flexibility to make decisions with regards to transferring patent rights to private agencies. Not all members of Congress approved of this plan. There were some who preferred that the title of the patent stay with the government; they were of the idea that if the government held the patents, it would mean an automatic dispersion of any knowledge gained from this research. Eventually, President Nixon's policy statement of August 1971, favored the flexible policy toward which he was inclined, but did not unify the discrepant policies which the various federal agencies followed [2].

Thus, even though the governments of John F. Kennedy and Richard Nixon brought about some changes, none were big enough to make a substantial impact.

The Institutional Patent Agreements or IPAs, were borne out of the ineffectiveness of the existing set of Technological Commercialization policies. The IPAs, were contracts agreed upon and put into place between individual federal institutions and individual universities. Though this arrangement worked on a short term basis, it was not the easiest to maintain. Each federal agency had its own set of rules and regulations and the process was slow. By 1978 , of the 28,000 patents held by the government, less that $5 \%$ had been licensed. Dissatisfaction was mounting with the incoherent patent transfer policy [2].

\section{The Enactment}

By the end of the 1970s, the interest that the IPAs generated, along with a strong sense that the US was being left behind in the field of technology led to an effort in Congress to bring about changes. In Washington there were serious concerns on the effects of this on American competiveness. Added to this was the fact that the government was seeing very little return on its yearly investment of $\$ 8$ billion. The lack of decision making on part of the Congress had led to no fewer than 26 sets of agency regulations to govern federal funded research making it a dysfunctional federal bureaucracy. On the whole there was a disinclination to rule that the researcher would hold the title to the patent [2]. This became the seminal issue in its debate. 
When the hearings on government patent policies regarding federally funded research and development, and its impact on innovation and commercial utilization of inventions resulting from this use of taxpayer dollars, gained momentum two clear objectives emerged. First was to move patents of the shelf off federal bureaucracy into the market place. Second was to draw a policy to strike a careful balance between the rights of the government to use inventions arising out of research that the government helped to support, and the equally important right of the public to see that the inventions realized their full potential in the marketplace and actually reached the people that they were intended to benefit. [4] After many trial and tribulations, the University and Small Business Patent Procedure Act (P.L. 96-517), also known as the Bayh-Dole Act was signed into law and came into effect in 1981[5]. The Bill is also known as the Bayh-Dole Act for its sponsors Robert Dole and Birch Bayh [2].

\section{Nuts and Bolts}

The Act brought about a cohesive set of rules, granting 'contractors' - be they universities or other non-profits or small businesses - the prerogative to hold the title to the patents. The architects of the Act were sensitive to criticisms arising from the possibility of granting licenses to a small number of powerful commercial organizations. In order to get this potential criticism out of the way, the 'contractors' were required by law to give preference to small business while making licensing decisions. The architects also included manufacturing preferences - if a product was to be sold in the US, US manufacturers were to be the first choice. The government had 'march-in-rights', and could under certain circumstance change a licensing decision made by the 'contractor' [2].

\section{What Really Worked?}

The jury is still out on the success of US Bayh-Dole act of 1980. Its deep effect on American economy \& competiveness is obvious, although critics still debate on reported numbers.

Let's look at some of the impact. There have been two primary methods applied to gauge the success of the Bayh-Dole Act [2,6].
a) Statistical Approach
b) Quality of Patents

a) Statistical Approach

- In 1980, the funding for academic research and development by American Universities was $14 \%$, by 2001 , it had gone up to $20 \%$ of the total [2]

- The number of patents issued each year to universities has gone up from 150 in 1981 to 3450 in 2003 [5] 
- Over half the university owned patents are licensed today, up from 5\% of the government owned patents which were licensed in 1978 [5, 6]

- A survey by the Association of University Technology Managers illustrates that by 1999 licensing activities generated $\$ 40.9$ billion worth of economic activity [5]

- Economic activity generated by academic licensing lead to the creation of 270,900 jobs [5]

- Resulted in tax revenues worth $\$ 5$ billion for the federal, state and local governments [5]

- Overall funding for academic research and development garnered from various sources - up from $\$ 6$ billion in 1980 to $\$ 33$ billion in 2001 [2]

As the above numbers illustrate, there has been a definite increase in many of the criteria that would be considered in order to ascertain whether the Bayh-Dole Act has been a success or not. For example - one of the intentions of the Act was to increase the licensing of federally funded innovations. By this criterion, the Act has had success over its predecessors, since as noted above, today half the patents owned by universities are licensed, as compared to $5 \%$ of what the government owned in 1978. We also see the benefits of the Bayh-Dole Act towards job creation, tax returns to the government, and economic activity generated.

b) Quality of Patents

The second criterion focuses at the quality of patents that have been filed since Bayh-Dole Act. The seminal work in this field belongs to Henderson, Jaffe and Trajtenberg (1998) [6]. These authors carried out research in 1998, studying the quality of patents filed. According to these authors, the way to estimate the quality of patents was to calculate the number of times the patent had been cited in later patents. This is considered to be a good measure, since higher the applicability of a patent towards future inventions, higher is the potency of the patent. If the number of patents since Bayh-Dole had increased, without much scope for viable future application of that research, then the research would have to be considered to have been watered down as compared to before the act was passed. According to the authors, by this measure, the quality of university patents declined after the Bayh-Dole Act came into force [7]. This study however was countered by authors, Mowery, Sampat and Ziedonis (2003), who studied citations for a longer period of time that the earlier study did. According to them, the quality of patents has not decreased, since the critical factor was that the longer the patent was out there, the higher the number of citations [7].

\section{Criticisms}

One of the biggest concerns regarding the Bayh-Dole Act has been - "Is the Act is ethical?" In his paper Michael Delaney (2005) says, academic research is considered a 'public good'. When the public good argument is taken into consideration, the privatization of scientific study aided by government funds, as advocated by the Bayh-Dole Act, flies in the face of 
the 'public good' argument [8]. The Bayh-Dole Act removes this 'knowledge' from the public domain, which is where it belongs and where it would be available to all, and puts it in the hands of private interests. Looking closely, universities have been patenting, what are known as 'upstream patents'. Upstream patents are patents where early stages of a product are patented. This allows the patent holder to license these patents out to entities which will use this knowledge to develop another product. Delaney also puts forth the concern that 'up-stream' patenting may hamper future innovations [8].

The Bayh-Dole Act provides the funding federal agency with 'march-in rights'. This gives the government the right to negate the preexisting licensing agreement and give it to another entity. The government can utilize this right only if it believes that the current licensee has no intention of marketing the product. 'Although to date, no federal agency has yet asserted its march-in rights' [2].

There have been three cases in the past where the National Institutes of Health (NIH), was appealed to. The first case, the appellant, Cellpro, charged that the university in question, Johns Hopkins, along with Baxter Healthcare had not carried out the required steps to market 'patented stem cell technologies' [2]. This case was dismissed by the NIH.

Another case involved Abbott Laboratories and Essential Inventions, which is a consumer advocacy group. Essential Innovations wanted Abbott Laboratories to sell their AIDS drug, Novir, for a lower price. Abbott Laboratories had recently increased the price of their drug $400 \%$. Though this effort on behalf of Essential Inventions received a smattering of support from members of Congress, this case was thrown out. The intent of the march-in right, as clarified by former Sen. Bayh, was to make sure that licensees didn't keep certain products off the shelves due to possible competition with existing products that the licensee already had out in the market. Though this might have been the original idea for adding these march-in rights, the government should consider the high costs that certain licensees charge and change that part of the Act [2].

In an example that strengthens the suggestion above - In the Case of Xalantan - the manufacturer of an anti-glaucoma drug, was brought to court over the fact that the prices charged in the US were higher than those charged by the same company for the same drug in Canada and Europe. This case was thrown out as well. This is a clear case of the tax payer having to pay twice, once in taxes to fund the research, and then having to pay high prices. Though these prices are market prices, the benefit to the taxpayer, at least in this one case is hard to see [2].

Since the beginning of the application of the Bayh-Dole Act, there has been an underlying fear that research in basic science may take a back seat to the commercial aspirations of the private sector. This would be a further erosion of the reason why Bayh-Dole came into effect in the first place. According to researchers Mowery and Sampat (2005), there has been no evidence that this kind of shift has taken place. One of the possible reasons that they give for this being the case is - a lot of the research has taken place in the biomedical 
sector, where basic and applied research are more closely related than in most other fields. [9]

Before Bayh-Dole Act came into play, there was a greater 'spirit of sharing' between scientists. Authors Mowery and Sampat (2005) fear that with commercialization being at the top of the agenda for many universities, the ideas of 'open science' are hindered.

Overall, we believe that as a policy directive to harmonize the distinct facets of policy to unbridle commercial innovation for large scale economic impact in a truly 'American' style competitive 'free market' environment, the Act of 1980 has had a significant sustainable positive impact. Major contributors to the contours of the Act have been, the existing enabling landscape of American government, education, research, patenting and technology commercialization infrastructure.

We acknowledge that there are major concerns with the Bayh-Dole Act. We observed that the Bayh-Dole Act's effects paradoxically impeded open collaboration, public good, a genuine competitive environment, and intellectual property rights. It skewed the public research funding towards activities in Pasteur's Fourth Quadrant, ignoring the inherent need of research funding in the other three Quadrants [3]. We believe that with philosophical underpinnings, mankind's perennial contemplation to navigate labyrinth of the above sensitivities will continue.

\section{Was There A Need For A Bayh-Dole Act?}

There have however always been questions as to whether such an act is needed to bring about the kind of changes the Bayh-Dole is credited with. According to Mowery and Sampat (2005), the US experience is unique and cannot be replicated anywhere else. We agree with this conclusion and believe it takes a number of unique enabling factors for such policies to be effective in a country. The collaboration between universities and industry has been present in the US for a very long time, and precedes the Bayh-Dole Act. This can be attributed to the unique nature of higher education in the US. The important factors that set the US educational system apart are - institutions of higher education are very varied, with many different leanings persisting amongst the different universities. Additionally, there has always been a healthy dose of competition existing between the institutions. The relationships that the universities fostered with state level officials added another dimension and brought about deeper alliances between the local universities and industrial and/or agricultural companies. Thus, industrial innovation and academic research have had a long standing symbiotic relationship with each other. All of these factors set the US higher educational system apart from that of the rest of the world [9]. One of the issues with the Bayh-Dole Act was the fear that it would impede collaboration, and openness in science. This fear along with the knowledge that many in the industry pay attention to publications and conferences could enhance the application of a similar act around the world. Any country looking to emulate the Bayh-Dole Act could embed in the policy, a push for collaboration. 
India's EMERging TeChnology Commercialization Policy:

Lessons From The American Model

One interesting fact is, when industry representatives were interviewed, they suggested that more than patents, most industries gave more importance to avenues such as publications, conferences and consultations [9].

US universities, as stated above, had started patenting with vigor in the 1970s - this applied to private as well as public universities. The lack of patenting framework in which most inventors found themselves led to a lobbying effort on part of universities to get Bayh-Dole Act passed. The passage of the act was part of the patenting and licensing phenomenon that was already taking place. This is borne out by two figures that authors Mowery and Sampat (2005) depict in their paper. One shows the share of US university patenting as a part of total US patenting. The figure shows no great or sudden climb in the number of patents filed post Bayh-Dole. The climb is gradual.

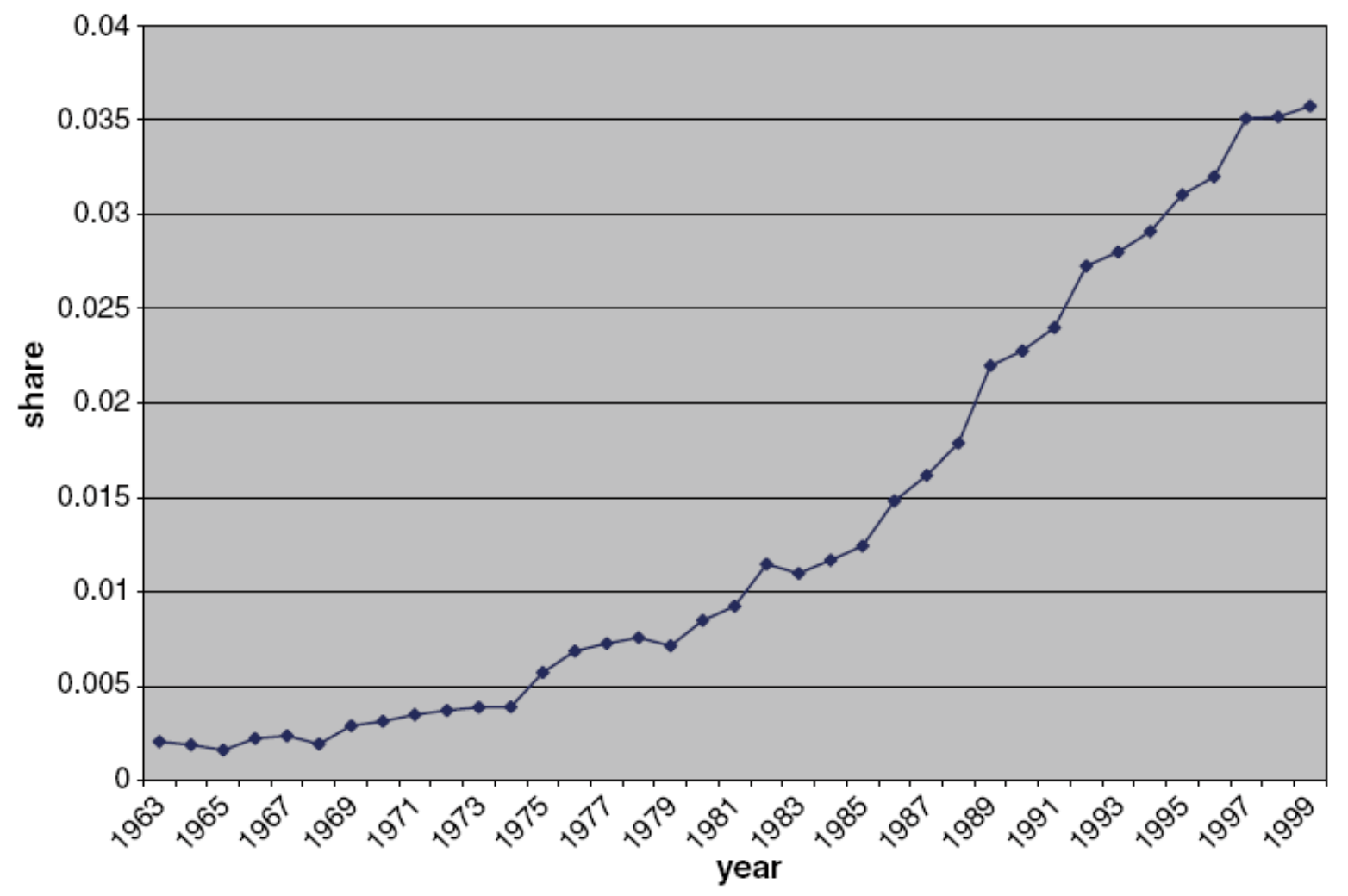
[12]

Figure 1. US research univ. patents \% of all domestic-assignee US patents, 1963-1999.

The same applies to the second figure, which depicts a rise in the "aggregate university patent propensity" after 1981. 


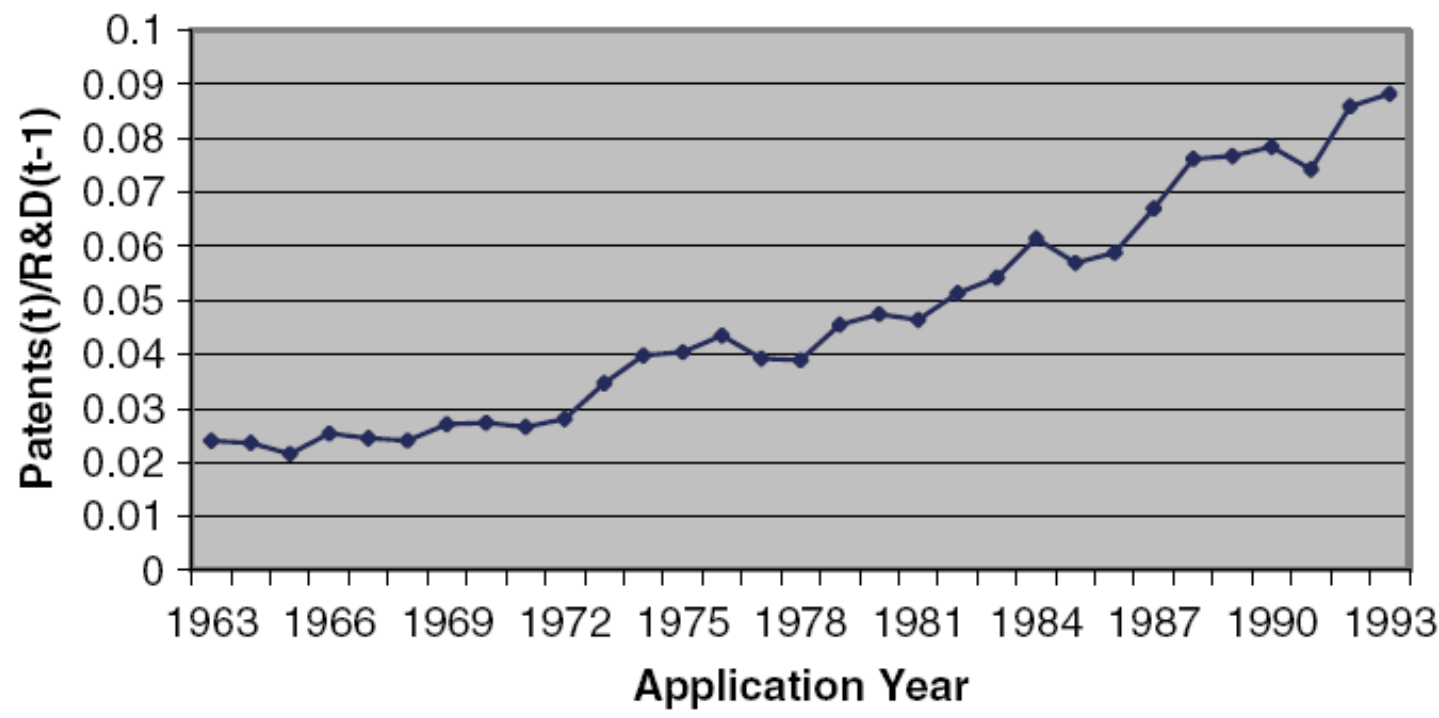

Figure 2. University patents per R\&D Dollar, 1963-1993.

[13]

Though this figure shows an increase, as in the first figure, it shows a very gradual increase which began before 1981, there is no 'structural break' in patent propensity [9]. This bears out the authors' claim that Bayh-Dole is part of the process, rather than the starting point of the process. It also gives credibility to their claim that the Bayh-Dole Act may not have been necessary at all.

We agree with this claim, but believe that though the Bayh-Dole Act was part of the process, it was a very important part of the process. Without this pivotal step the various policies that were in place would not have been streamlined, leading to continuing chaos. With the passage of the Bayh-Dole Act, there was now, one way to deal with the patenting of innovation.

\section{Lessons from the American Model}

- Bayh-Dole act was successfully able to harmonize different technology commercialization policies existing at that time.

- Bayh-Dole act was successfully able to fix issues in Stage 2 of the technology commercialization process. Specifically it allowed more patents to move from the federal bureaucracy into the marketplace. This factor alone is credited with having had a significant effect on the cumulative economic impact.

- By the time Bayh-Dole was envisioned, the US already had a set of enabling factors in place. We believe these enabling factors coupled with the Bayh-Dole act was a potent recipe. We will next look at these factors. 


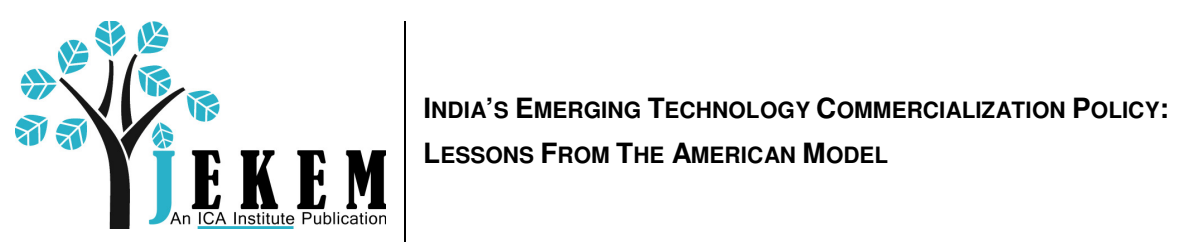

\section{Enabling Factors}

- Culture of Innovation: Be it the independent thinking imbibed though the American education system, or national leaders extolling the virtues of science and technology, America has had a pronounced culture of innovation. It's focus, from pumping funding into $\mathrm{R} \& \mathrm{D}$, to setting up premier institutions of higher learning, has been on pushing the envelop just a little bit further. That has also led to a culture of collaboration between academia, government and industry.

- Federal Bureaucracy: Over the course of the years, the US has been able to set up an institutional 'system' to administer government funding for $\mathrm{R} \& \mathrm{D}$ and patents. We may take these institutions for granted here in US, but when you look at the bigger picture of establishing the technology commercialization process, they still hold a lot of value. In the absence of such institutions, policies would merely be on paper. A fair, effective implementation of a policy cannot be envisioned without a stable 'Federal Bureaucracy' as its backbone. We use this term to cover the entire network of institutions.

- Patents Administration: Awarding the right to 'hold a patent' on a certain invention, is akin to awarding the right to own a 'piece of land'. This process of administering the various aspects of patents, becomes a significant one, when you take into account the value of the assets under consideration :

The process entails :

P Process of awarding patents rights

○ Process of monitoring those in the marketplace

○ Keeping records

- Process of infringement redressal

Again as with previous factors, absence of a well defined process can lead to mistrust on the part of stakeholders. This essential factor was found to be firmly in place in the US.

We believe that each county is unique and sovereign. But we can learn \& adapt from each other's experiments. In the following sections we will explore India.

\section{India: The Emerging Giant?}

In 2009, India's new Minster of Science \& Technology, Kapil Sibal, expounded in a speech to The Indus Entrepreneurs (TiE) in New Delhi, "Our technological, demographic and entrepreneurial advantages are huge. This is our collective fact of advantage which can propel as valued participants in the innovative global economy and the turning point in 
achieving our nation's fortunes. We now need to focus and concentrate on leveraging our strengths and opportunities to unleash India's innovation potential."

India is in many ways dealing with similar challenges that America was dealing with in the lead up to Bayh-Dole Act. India's situation is however quite unique in the world. In the following sections we will examine the relevance of the Bayh-Dole Act for India. Is the US Bayh-Dole really relevant in India?

In recent years the Indian economy has changed tremendously. From the protected, coddled economy of the pre-liberalization era, India has gone to being an economic behemoth today. The potential was always there, large geographic mass, a seething population waiting to get its teeth into the world, democracy, and a thirst to prove itself. Today, India is one of the largest economies in the world. The economy has grown at an astonishing pace of $9.6 \%$ in 2006, and $9.2 \%$ in 2007 [14]. It is also the $4^{\text {th }}$ largest economy based on Purchasing Power Parity (PPP) [14].

The Indian economy is however riddled with dichotomies. While it is the $4^{\text {th }}$ largest economy based on PPP, it is also the country where, according to a recent report by an NGO, 200 million people go without enough food each day [15, 16]. India remains an economy largely dependent on farming $-70 \%$ of the population lives in the villages, and $60 \%$ of the employable population works in the agrarian sector. With an average per capita income of \$ 720, India is still a 'low-income' level country [16].

Consider the following facts from McKinsey's Global Institute report titled 'The Bird of Gold: The rise of India's Consumer Market'.

India will go from $12^{\text {th }}$ largest consumer market to $5^{\text {th }}$ largest by 2025. Dramatic expansion of domestic consumption will be seen. Driven by-

1. Rising household incomes - which will lead to the creation of a large middle class and increased per-capita spending

\section{Growth in population}

From 1995-2005, consumption has accounted for over 50\% of the GDP growth. Consumption will increase at a rate of $7.3 \%$ annually until 2025. India is in virtuous long term cycle in which rising incomes lead to increasing consumption which in turn creates more opportunities and employment further fuelling GDP and income growth. Over 290 million people will go from being very poor to having a sustainable life. The middle class will rise to over 580 million people. Rising incomes will be the biggest factor in increased consumer spending - 80\% of this rise will come from rising incomes, and $16 \%$ due to increase in number of households. In the past, incomes have not grown on par with the growth in the economy. This is because businesses get a bigger share of total income during periods of high growth. They generate profits that are put into investments. Thus this kind of growth takes time to trickle down as increased wages and household incomes. As time goes on however, household incomes will start to rise. 


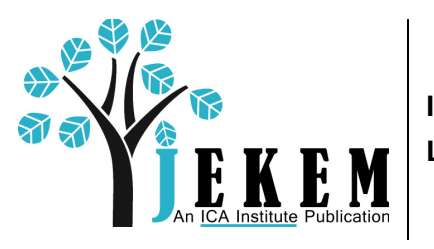

India's Emerging TeCHNOLOgY Commercialization Policy:

Lessons From The AMERICAN Model

The above data explains India's current socio-economic conditions. It also clearly points out that domestic consumption (of products and services) has been the fulcrum of India's rising medium incomes. For a developing country, moving large sections of population to the next slab of income level is a definite path to large scale poverty alleviation. We believe that effective Technology Commercialization can contribute to that positive trend.

\section{India's R\&D Expenditure Indicators}

\section{Figure 1.4 R\&D Expenditure in India, 1990-2005}

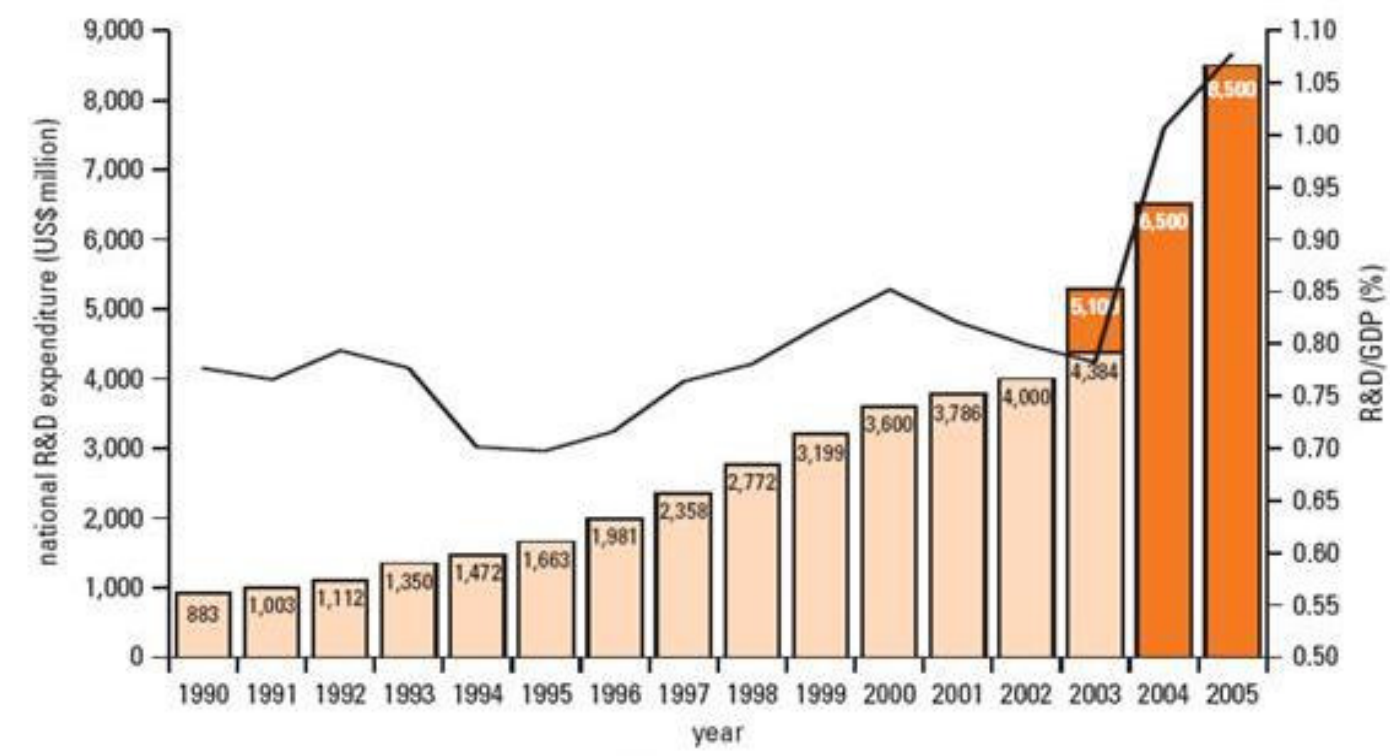

\footnotetext{
$\square$ government $R \& D$ number $\square$ Evalueserve R\&D estimate $-R \& D / G D P$

Source: Department of Science and Technology 2006; Evalueserve 2006.
}

Figure 1. R\&D Expenditure in India, 1990-2005

As evident from the figure above, India's R\&D expenditure has definitely shown a marked increase since 2003. Although in absolute terms it stands just above $1 \%$ of the total GDP (circa 2005). If India needs to get on the fast track to global competitiveness, this certainly needs to be significantly higher. We will include this factor in our policy recommendations later in the paper.

- India's R\& D expenditure as compared to other countries 
Another frame of reference used is the combined factor of researchers per million population and $R \& D$ budget as percentage of GDP (in PPP terms). As the following table illustrates, India is at the rock bottom in research expenditure as compared to the other countries. Its implications are clear with regards to the magnitude of leap India that needs to take to be in the company of even other developing economies. (Figure 2)

Figure 1.3 R\&D Effort in Various Countries, 2004

(total gross domestic expenditure on $R \leftrightarrow D$ in purchasing power parity dollars)

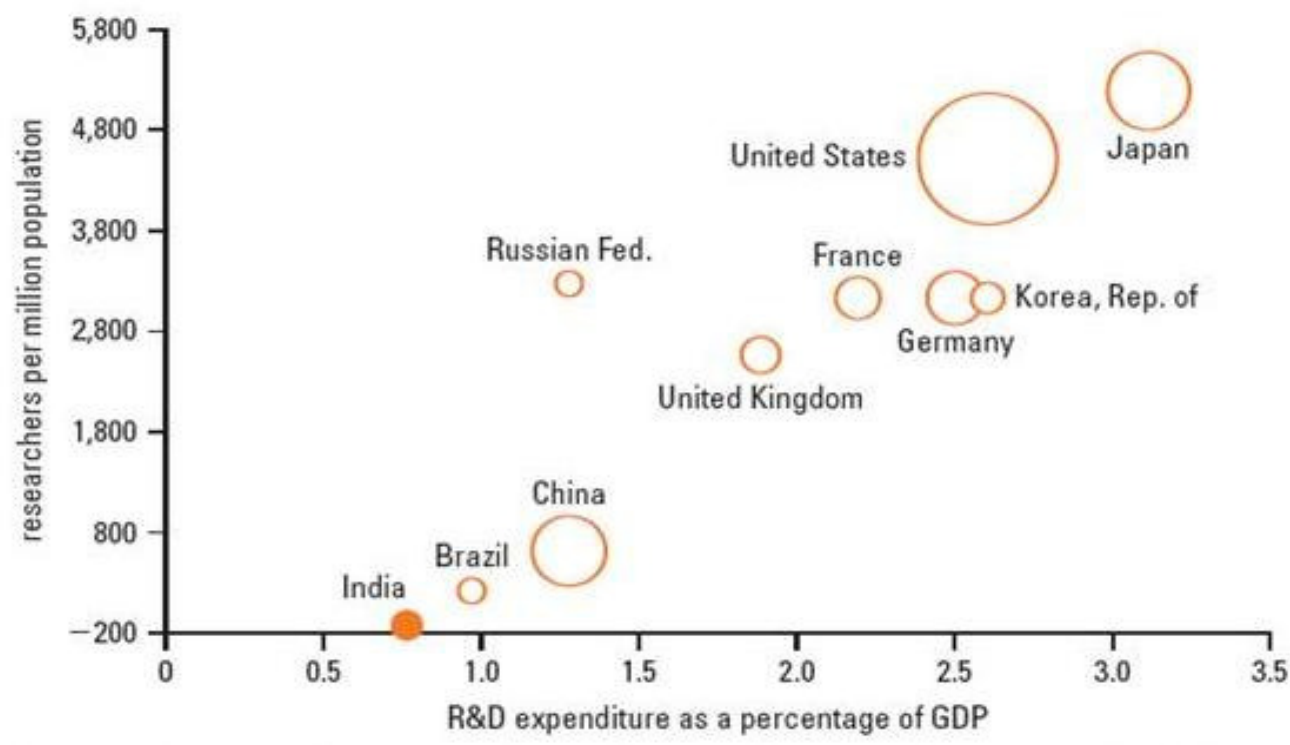

Source: Calculated from R\&D as percentage of GDP and GDP in purchasing power parity (PPP) terms, data from World Bank (2006h).

Note: The size of the bubbles represents the gross amount spent on R\&D in 2004 in PPP terms.

Figure 2. R\&D Effort in Various Countries, 2004

\section{The Contours of India's Emerging Technology Commercialization Policy}

\section{What does the Indian PUPFIP bill say?}

The PUPFIP bill : The Protection and Utilization of Public Funded Intellectual Property Bill 2008 [28]. The aim of the bill is to engender innovation and creativity to help India compete in the global arena [29]. According to the bill, innovation needs to be safeguarded and made available for use, in order to encourage an interest in research and development. Through this bill, the government aims to provide rights to those involved in research and 
development and to encourage production of intellectual property and its commercialization. The bill endeavors to increase alliances between the government, private sector and NGOs. It attempts to promote innovation carried out by SMEs, and to market inventions and research, that come out of government funded projects. In order to create an environment conducive to innovation, the bill will attempt to raise the profile of intellectual property in universities and other institutions devoted to research. This in turn would put the onus of promoting the importance of innovation among students on these institutions and universities. In order to decrease reliance on government aid to carry out research, the bill hopes that the royalties and premiums from inventions will provide the necessary money for future research and development.

It is also stated in the objectives that 'the ultimate objective, however, is to ensure access to such innovation by all stakeholders for public good' [29].

\section{Provisions under the bill}

1. It awards the patenting rights to innovations coming out of government funded research to the academic institutions instead of the government

2. The institution creating the innovation has to inform the appropriate government funding agency of the creation of the invention within 60 days of doing so

3. If the institution intends to patent the invention, the government agency has to be informed within 90 days of the invention being created

4. If the institution carrying out the research fails to inform the government agency, under certain prior acts, the government will take on the title to the patent. If there is an adequate reason why the research and development facility did not disclose the innovation in time, the government may rule that the title can vest in the name of the facility.

5. The bill makes an exception to the clause vesting the title in an institution - if the institution is not situated in India, does not have an office in India or is answerable to another government.

6. According to the bill, the inventor is guaranteed at least $30 \%$ of the royalties. If there is an agreement between the inventor and the research facility, which was granted funding, the inventor maybe entitled to more than $30 \%$ [30]

7. Within 180 days of receiving funding, the organization receiving the government funds has to form an 'intellectual management committee' to process the innovations coming out of such research in terms of allocation of rights, marketability and to supervise licenses [30]

\section{Criticisms of the India's Public Funded Intellectual Property Bill 2008}

The current form of the PUPFIP Bill has generated a lot of criticism. One of the first criticisms of the bill is the secrecy in which the bill was approved - no official draft was 
made available, nor was there any open debate $[28,30]$. There is also fear that the industry will dictate the kind of research that is carried out and that there is no provision for the government to steer the course of publicly funded research [31]. One newspaper points out as an example the '90/10 gap', which shows succinctly how ninety percent of the research money going into the medical arena, goes to problems affecting the richest ten percent of the world [28]. This is a major concern since, in the past the Indian government has ruled in favor of not patenting drugs, so that they could be made available at lower prices. Since one of the main aims of this Bill is the commercialization of innovations, there is fear that the public health concerns and priorities may be ignored, to the detriment of not only the citizens of India, but also other developing countries [31]. Another concern regarding the Bill is the non-disclosure requirements that the government insists that the innovating organization must follow. The invention cannot be publicized until the patent title is vested [32]. The fear is that this stipulation will stifle academic exchanges and increase bureaucracy, thus suppressing innovation [28]. There is concern amongst those whom this would affect the most. Researchers and academics are not necessarily convinced that the PUPFIP Bill will be advantageous, and echo the fears of business interests taking over research [31, 33]

Next we look at India's contextual and enabling factors in unleashing its innovation.

\section{Unleashing India's Innovation}

As we look for effective solutions to unleash India's innovativeness, we will take a look at three main sources.

1. Implementing enabling factors which allowed the US to efficiently leverage their policy

2. Applying the lessons learned from the American model

3. The World Bank's framework in its book - "Unleashing India's Innovation Growth Potential"

\section{Implementing enabling factors which allowed the US to efficiently leverage their policy}

In the earlier sections we identified the following Enabling Factors. India will be served well by developing these further along with the policy framework.

- Culture of Innovation: This factor speaks to the culture of innovation in a country's education policy; it's institutions of higher learning and its R\&D institutions. Although India prides itself on some of the best in class institutions, in these aspects the authors believe that a cultural shift needs to take place in order to leverage the upcoming technology commercialization policy. Also, there needs to a more concrete bridge between academia and industry in India. 
- Federal Bureaucracy: Institutions are the backbone of any policy framework. Although they are in place, India needs to strengthen the awareness, the reach and the effectiveness of these institutions. The figure below lays out India's premier research institutions which contribute to creation and commercialization activities. In order to focus heavily on 'Commercialization' activity we need to look closely at such an institutional infrastructure. Advisory and implementation agencies play a key role in governing the scale, efficiency and quality of such programs.

India's primary Technology Commercialization and Licensing agencies are

- Office of the Controller General of Patents, Designs \& Trade Marks

- Council of Scientific and Industrial Research (CSIR)

- Dept. of Science and Technology

We detail recommendations about such agencies further in the paper. 
(Figure

3)

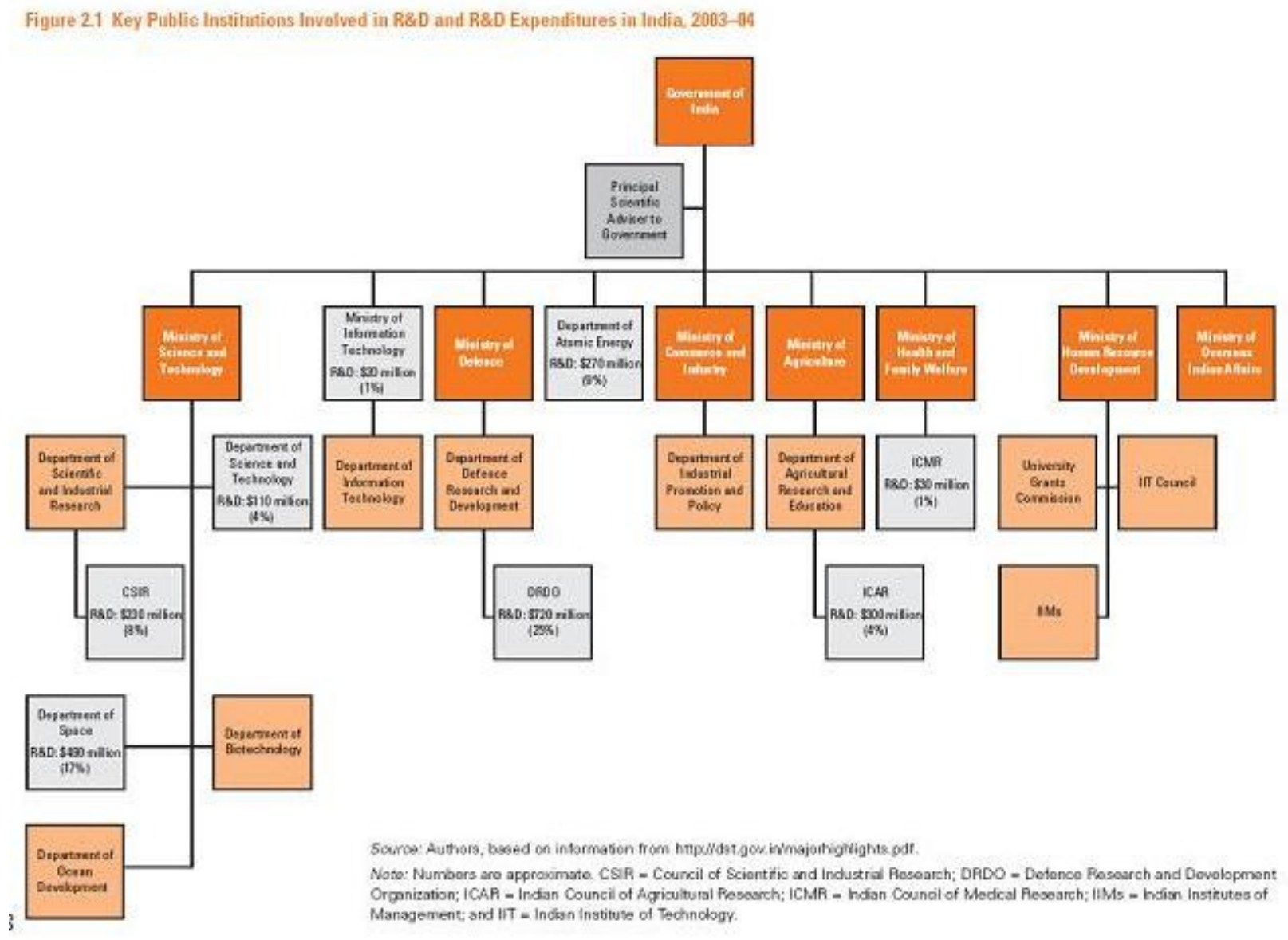

Figure 3. Key Public Institutions Involved in R\&D and R\&D

Expenditures in India, 2003-04

Patents Administration: This factor details the following processes:

○ Process of awarding patents rights

○ Process of monitoring those in the marketplace

○ Keeping records

○ Process of infringement redress 
Again, as with the above factor, these processes may be in place in India, but the awareness about these processes need to be strengthened at India's grassroots. Absence of a well defined process can lead to mistrust on the part of stakeholders. This essential factor was found to be firmly in place in the US.

\section{Applying the lessons learned from the American model}

According to the India's Science and Technology policy of 2003, 'A strong base of science and engineering research provides a crucial foundation for a vibrant programme of technology development. Priority will be placed on the development of technologies which address the basic needs of the population; make Indian industries - small, medium or large - globally competitive; make the country economically strong; address the security concerns of the nation.' The policy goes on to say that technology must benefit all equally and be accessed by the 'disadvantaged' sections [17].

With the introduction of draft PUPFIP Bill, this movement is talking another turn. It stands at a similar stage, where America stood before the Bayh-Dole act

- US Bayh-Dole act was successfully able to harmonize different technology commercialization policies existing at that time. Indian PUPFIP Bill ideally should have a similar catalyst effect.

- Bayh-Dole act was successfully able to fix issues in Stage 2 of the technology commercialization process. Specifically, it allowed more patents to move from the federal bureaucracy into the marketplace. This factor alone is credited to have had a significant effect on the cumulative economic impact

- As we pointed out in the earlier section, India needs to improve its return on investment in R\&D. Strengthening this factor can potentially have this impact.

It is interesting to note that a lot of attention is been given to getting India to unleash its innovation. As the world recognizes its potential, it also notices the unprecedented unmatched impact it can leave as a model of mass scale poverty alleviation program.

\section{The World Bank's Framework}

In the recently published book titled "Unleashing India's Innovation Growth potential" the authors outline broadly based innovation activities. They propose two separate set of activities

- Creation and Commercialization

- Diffusion and Adoption

Although both the factors are equally important we submit that given India's current scenario, it's advisable to focus highly on "Creation and Commercialization" activity first. 
This will primary focus will ensure channeling millions of young minds to harness their energies for a national challenge. Presented next is the comprehensive framework proposed in the 2006 World Bank published book entitled, "Unleashing India's innovation potential". As shown in Figure 5, the detailed framework lists the enabling environment for innovation: policies, institutions and capabilities. We acknowledge that it's a comprehensive framework and will seek to focus on its various layers and enhance it's practicality for policy makers.

\section{Table 1.5 The Enabling Environment for Innovation: Policies, Institutions, and Capabilities}

\begin{tabular}{|c|c|c|c|}
\hline $\begin{array}{l}\text { Components of } \\
\text { enabling environment }\end{array}$ & Policies & Institutions & Capabilities \\
\hline $\begin{array}{l}\text { Creation and } \\
\text { commercialization of } \\
\text { new knowledge }\end{array}$ & $\begin{array}{l}\text { - Policies to promote } \\
\text { more private R\&D } \\
\text { Intellectual property } \\
\text { rights regime } \\
\text { Matching grants } \\
\text { - Tax subsidies } \\
\text { - Public spending on R\&D } \\
\text { National mission } \\
\text { programs } \\
\text { Competitive grants } \\
\text { - Peer reviews } \\
\text { innovations }\end{array}$ & $\begin{array}{l}\text { - Public labs, universities } \\
\text { - Private R\&D labs } \\
\text { - IPR institutions } \\
\text { - Technology transfer offices } \\
\text { - Science and technology parks } \\
\text { - Technology incubators } \\
\text { - Research and education } \\
\text { networks } \\
\text { - Specialized nongovernmental } \\
\text { institutions } \\
\text { - Grassroots networks } \\
\text { - Early-stage technology } \\
\text { development finance } \\
\text { and venture capital }\end{array}$ & $\begin{array}{l}\text { - High-level human } \\
\text { capital for R\&D } \\
\text { (scientists, } \\
\text { engineers, } \\
\text { technicians) } \\
\text { - Techno- } \\
\text { entrepreneurship }\end{array}$ \\
\hline $\begin{array}{l}\text { Diffusion and } \\
\text { absorption of existing } \\
\text { knowledge in new } \\
\text { locations }\end{array}$ & $\begin{array}{l}\text { - Openness to global } \\
\text { knowledge flows } \\
\text { Trade } \\
\text { Foreign direct } \\
\text { investment } \\
\text { Technology } \\
\text { licensing policy } \\
\text { - Internet access } \\
\text { - Foreign education and } \\
\text { attracting the diaspora }\end{array}$ & $\begin{array}{l}\text { - Technical information } \\
\text { - Tervices } \\
\text { - Produclogy upgrading } \\
\text { - Metrology, standards, testing, } \\
\text { - and quality control systems } \\
\text { - National research and } \\
\text { - Nducation networks } \\
\text { - Tetworks at cluster level } \\
\text { finance for micro, small, } \\
\text { and medium enterprises }\end{array}$ & $\begin{array}{l}\text { - Formal education } \\
\text { and skills } \\
\text { - Engineering } \\
\text { consulting firms } \\
\text { - Business support } \\
\text { services }\end{array}$ \\
\hline $\begin{array}{l}\text { Broader investment } \\
\text { climate }\end{array}$ & $\begin{array}{l}\text { - Competition and trade } \\
\text { - Regulatory policies. } \\
\text { especially toward } \\
\text { infrastructure } \\
\text { - Entrepreneurship support } \\
\text { - Good rule of law } \\
\text { - Macroeconomic stability }\end{array}$ & $\begin{array}{l}\text { - Efficient financial system } \\
\text { - Flexible labor market } \\
\text { - Effective courts and judiciary } \\
\text { - Market-responsive formal } \\
\text { education institutions and } \\
\text { lifelong learning system }\end{array}$ & $\begin{array}{l}\text { - Literacy } \\
\text { - Secondary and } \\
\text { higher education } \\
\text { graduates } \\
\text { - Managers } \\
\text { - Entrepreneurs }\end{array}$ \\
\hline
\end{tabular}

Source: Authors.

(Figure 4) 


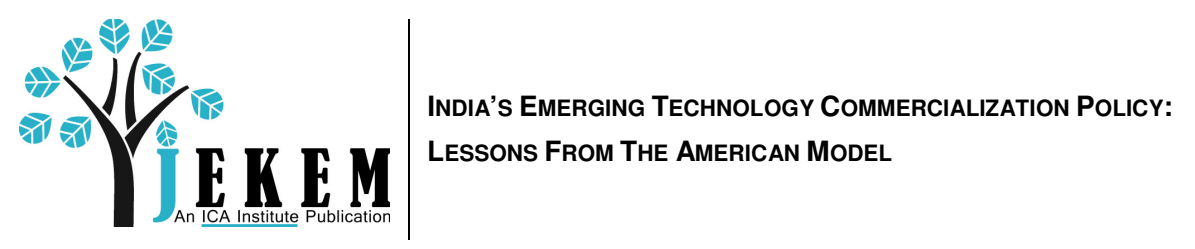

Figure 4. The Enabling Environment for Innovation: Policies, Institutions, and

\section{Capabilities}

\section{Practical additions to the World Bank's Framework}

In 2008, India's then Union Minister for Science, Technology, and Earth Sciences, Kapil Sibal announced in a speech to TIE (New Delhi),

"I had requested FICCI to draft an Innovation Law, which they have done. We in the Ministry are now endeavoring to initiate legislation for giving effect to this draft law."

We recognize that this as a significant development and recommend the policy makers to take into account India's unique economic, demographical, educational \& scientific scenario while drafting such legislation.

It is evident to the authors that India needs to place a high priority on deriving "Large Scale Inclusive Economic Impact" from its proposed innovation legislation. The following schematic recommends a structural basis for understanding the intended impact (Figure 5)

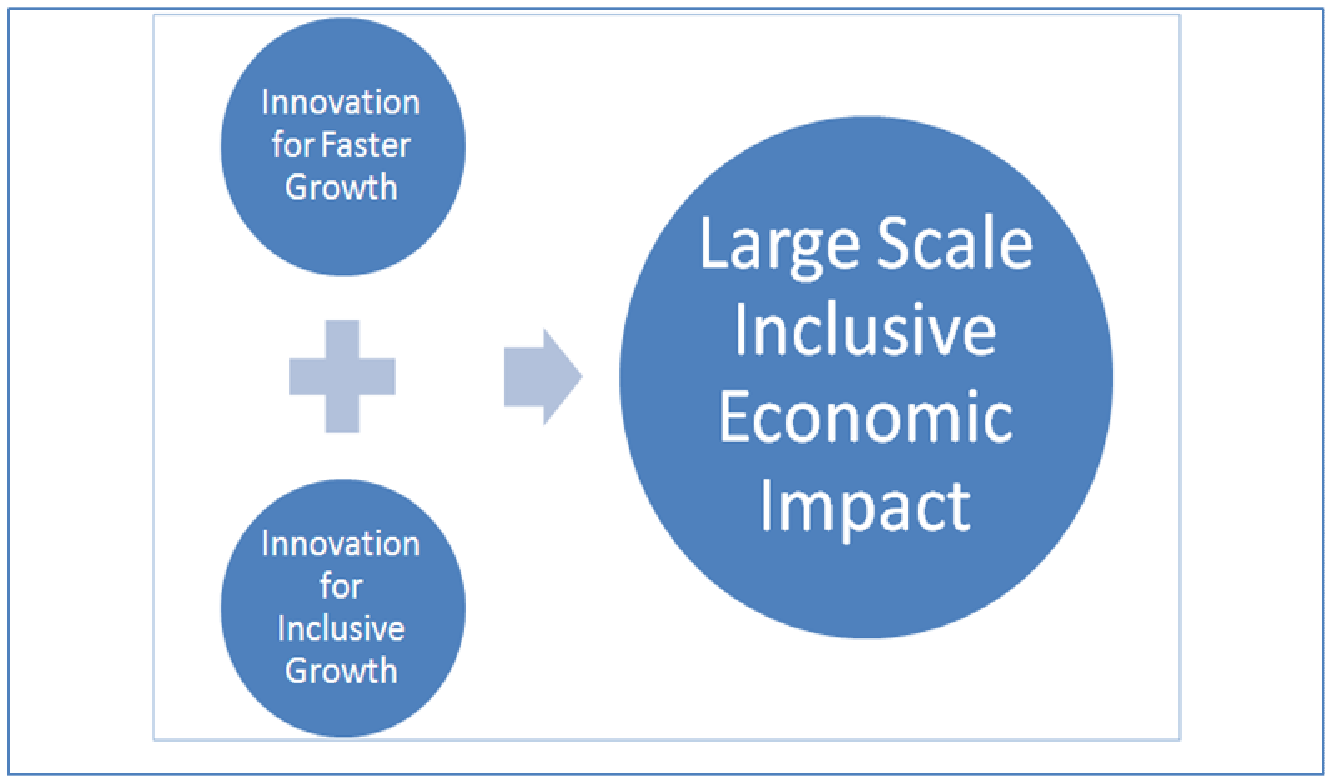

Figure 5. Large Scale Inclusive Economic Impact

The next schematic presents the essential ingredients to effectively achieve the Large Scale Inclusive Economic Impact Mix 
(Figure 6)

\section{Large Scale Inclusive Economic Impact Mix}

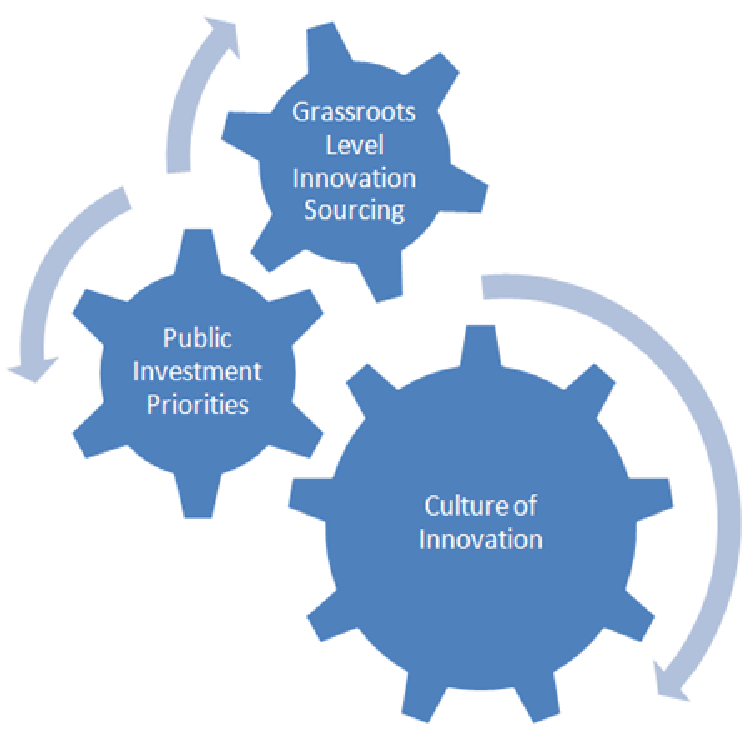

Figure 6. Large Scale Inclusive Economic Impact Mix

\section{Policy Action}

In the light of upcoming legislative deliberations we propose the following action items. Readers will notice the common themes reoccurring from above in this section. These recommendations are based on our understanding of India's current scenario and the success factors in America's experience in this arena. We see the following three areas as the essential immediate impact points

- Policy Harmonization

- Steady Budget Increase

- Enforcement Institutions

The following slide details actions for each of the areas identified above. 
(Figure

7)

\section{Policy Action}

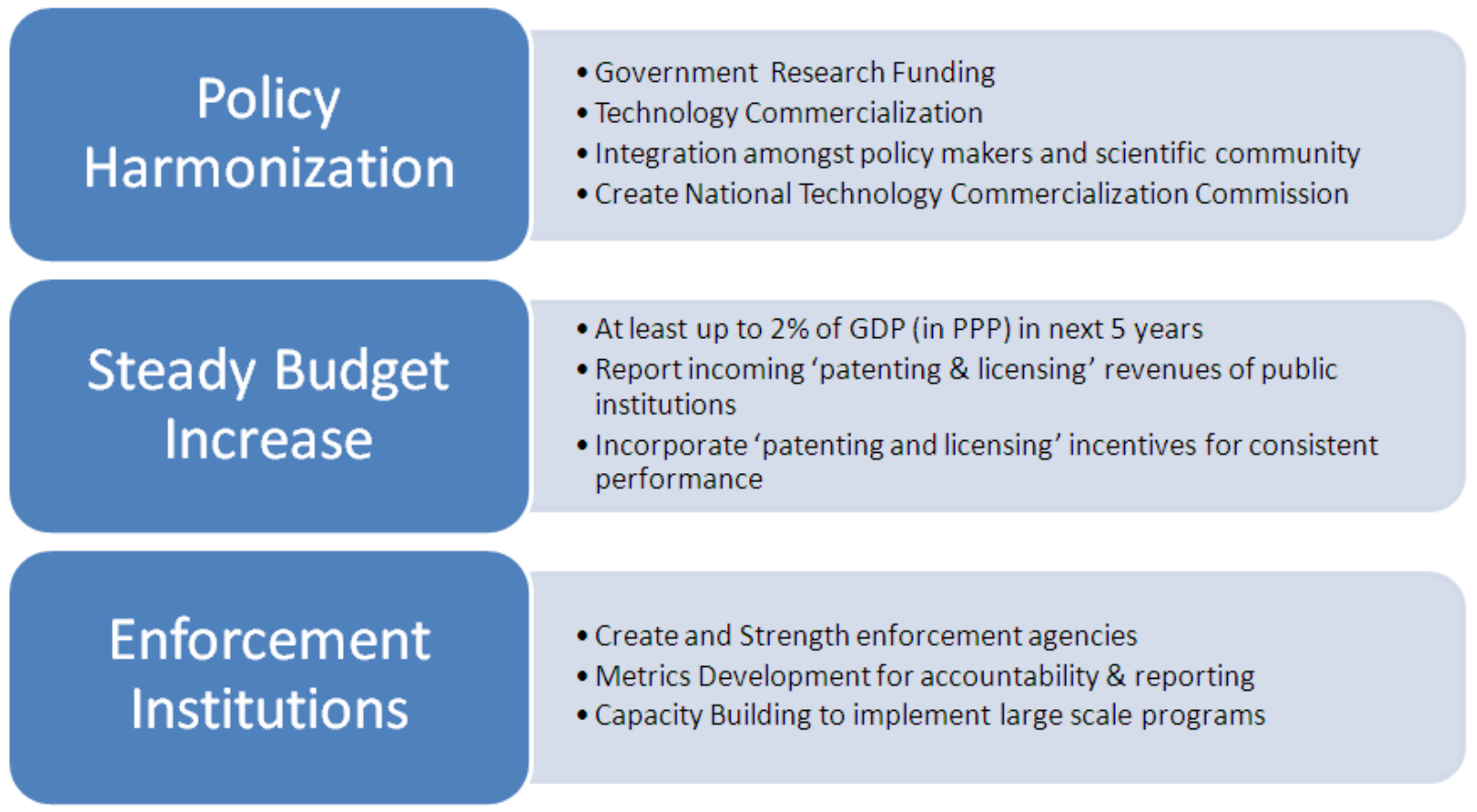

Figure 7. Policy Action

\section{Conclusion \& Future Work}

The authors acknowledge that several aspects of the above recommendation merit further explanation. It's evident that the scope and nature of this review paper is wide. The authors intend to further study the research questions outlined and present their findings. 


\section{Bibliography}

1. The Bayh-Dole Act at 25. 2006, BayhDole25, Inc: New York, New York, USA. p. $1-44$.

2. BayhDole25, I., The Bayh-Dole Act at 25. 2006, BayhDole25, Inc.

3. Tierney, W.G., Pasteur's Quadrant: Basic Science and Technological Innovation/Chaos of Disciplines, in Academe. 2005, American Association of University Professors: .

4. Bayh, B. Bayh-Dole +25 .

5. Bayh, B., Bayh-Dole +25 , in Innovation: America's Journal of Technology Commercialization. 2005, Coleman Travelstead.

6. Mowery, D.C., B.N. Sampat, and A.A. Ziedonis, Changes in University Patent Quality After the Bayh-Dole Act: A Re-Examination. International Journal of Industrial Organization, 2003. 21(9): p. 1371-1390.

7. Campbell, K.D. (1998) TLO says Government Research Pays off Through $\$ 3$ Billion in Taxes. MIT News Office Volume,

8. Devaney, M., Government Subsidized Academic Research: Economic and Ethical Conflicts. Journal of Academic Ethics, 2004. 2: p. 273-285.

9. Mowery, D.C. and B.N. Sampat, The Bayh-Dole Act of 1980 and UniversityIndustry Technology Transfer: A Model for Other OECD Governments. Journal of Technology Transfer, 2005. 30 1/2: p. 115-127.

10. Siepman, T.J., The Global Exportation of the U.S. Bayh-Dole Act. University of Dayton Law Review, 2004. 30(2): p. 209-243.

11. Ollier, P. (2009) Bayh-Dole Comes to Asia (full version). MIP Week Volume,

12. Mowery, D.C. and B.N. Sampat, U.S. Research Univ. Patents \% Of All DomesticAssignee US patents, 1963-1999, -. U.S. Research Univ. Patents \% Of All DomesticAssignee US patents, Editor. 2005, Springer Netherlands.

13. Mowery, D.C. and B.N. Sampat, University Patents Per R\&D Dollar, 1963-1993, -. University Patents Per R\&D Dollar, Editor. 2005, Springer Netherlands.

14. EconomyWatch.com. Indian Economy Overview. [cited 2009 August 14, 2009]; Available from: http://www.economywatch.com/indianeconomy/indian-economyoverview.html.

15. BBCNews. Report Highlights Hunger in India. 2009 [cited; Available from: http://news.bbc.co.uk/2/hi/south asia/8178072.stm. 
16. Dutz, M.A. and C. Dahlman, The Indian Context and Enabling Environment, in Unleashing India's Innovation (Toward Sustainable and Inclusive Growth), M.A. Dutz, Editor. 2007, The World Bank: Washington, DC, USA. p. 23-48.

17. Agarwal, S.P. and A. Gupta, Policies And Mechanisms For Technology Transfer To SMEs In A Globalizing Economy - Indian Pespective, in Transfer of Technology - Major Country Case Studies, A. Heshmati, Y.-B. Sohn, and Y.-R. Kim, Editors. 2007, Nova Science Publishers, Inc.: New York. p. 133-156.

18. India, G.o., Micro, Small and Medium Enterprises in India - An Overview, O.o.D.C. (MSME), Editor. 2007: New Delhi, India.

19. Dutz, M.A., Overview: Toward an Action Agenda for Innovation, in Unleashing India's Innovation (Towards Sustainable and Inclusive Growth), M.A. Dutz, Editor. 2007, The World Bank: Washington, DC, USA. p. 5-25.

20. Dahlman, C., M.A. Dutz, and V.K. Goel, Creating and Commercializing Knowledge, in Unleashing India's Innovation (Toward Sustainable and Inclusive Growth), M.A. Dutz, Editor. 2007, The World Bank: Washington, DC, USA. p. 49-83.

21. Balachandran, A., TePP - India's Largest Open Innovation Program, in TePP eNEWS, D.o.S.a.I. Research, Editor. 2009: Vellore, Tamilnadu, India. p. 1-10.

22. Winentrance.com. Department of Biotechnology - Small Business Innovation Research Initiative. [cited; Available from: http://www.winentrance.com/news/Department-Biotechnology-SBIRI.html.

23. India.gov.in, Technology Development and Demonstration Programme: Ministry of Science and Technology.

24. SIDBI. FAQ - Answers. [cited 2009 August 14, 2009]; Available from: http://www.sidbi.in/faqans.asp.

25. SIDBI. Bills Finance Scheme. [cited 2009 August 11, 2009]; Available from: http://www.sidbi.com/bills.asp.

26. Goel, V., C. Dahlman, and M.A. Dutz, Diffusing and Absorbing Knowledge, in Unleashing India's Innovation (Toward Sustainable and Inclusive Growth), M.A. Dutz, Editor. 2007, The World Bank: Washington, DC, USA. p. 83-103.

27. Board, N.S.a.T.E.D., Institutional Mechanism: Science and Technology Entrepreneurship Park, D.o.S.a. Technology, Editor. 2002: New Delhi, India.

28. Abraham, S. and P. Prakash, Does India need its own Bayh-Dole?, in Indian Express. 2009, Indian Express Newspapers (Mumbai) Ltd. .

29. Sibal, K., The Protection and Utilization of Public Funded Intellectual Property Bill 2008, S.T.a.E. Sciences, Editor. 2008: New Delhi, India. 


\section{Journal of Emerging Knowledge on Emerging Markets, Vol. 2 [2010], Art. 10 \\ INDiA's Emerging TeCHNOLOgY Commercialization Policy: \\ Lessons From The American Model

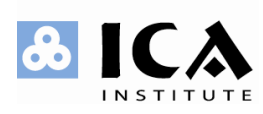

30. Vartak, R. and M. Saurastri, The Indian Version of the Bayh-Dole Act, in Intellectual Asset Management. 2009, Gavin Stewart. p. 62-64.

31. Butkus, B. As India Mulls Bill Modeled on Bayh-Dole, Critics Claim It May Stifle Innovation. Biotech Transfer Week 2008 [cited 2009 August 10, 2009]; Available from: http://www.genomeweb.com/biotechtransferweek/india-mulls-bill-modeled-bayh-dolecritics-claim-it-may-stifle-innovation.

32. Nair, M.S., Protecting Public Funded Intellectual Propery in India, in ipFrontline Magazine. 2009.

33. Jishnu, L., Does India need a Bayh-Dole Act?, in Business Standard. 2008, Business Standard Ltd. (BSL): New Delhi, India. 